Original Article

\title{
Altered olfaction, obesity, and glycosylated hemoglobin; Indicators of accelerated ageing in apparently healthy, Pakistan's young aged population.
}

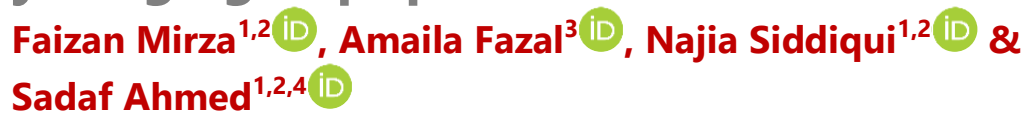

\section{Abstract}

Background: Obesity is an associated risk of devastating diseases and increased mortality. Thereby, the study objective was to evaluate the predisposing obese individuals towards accelerated ageing and determine the smell test as the possible indicator for early biological ageing.

Methodology: This was a descriptive cross-sectional study carried out in Karachi, Pakistan, from $8^{\text {th }}$ June 2016- $4^{\text {th }}$ December 2019. A total of 412 individuals were included in the study. The data for age, gender, body mass index (BMI), sniffing score, and hemoglobin A1c (HbA1c) levels were collected from the target population. The screening 12 test was intended to be used for the examination of smell disorders in humans. The test results were used to differentiate between Normosmia, Hyposmia, and Anosmia.

Results: Four hundred and twelve participants were recruited in the study with a mean age of $32.65 \pm 12.6$ years and divided into three age groups; 20 to 36, 37 to 53, and 54 to 70 years. There were 194 (47.1\%) females and 218 (52.9\%) males. Out of the total, $19.9 \%$ of individuals were underweight, $58.5 \%$ were normal, $21.6 \%$ were overweight. It was also observed that of the total, $24 \%$ of participants were pre-diabetic. Cross analysis of the variables showed that the olfaction decreased as the BMI was increasing ( $p=0.000$ for obese). Conclusion: As the sense of olfaction decreased with an increase in BMI and HbA1c levels, it was concluded that obese individuals have an increased predisposition towards accelerated ageing and the increased risk of predisposition to diabetes to obesity significantly accelerate the process of biological ageing.

\section{Keywords}

Ageing, Diabetes, Glycosylated Hemoglobin Levels, Obesity, Sniffing Score.

\section{Check for updates}




\section{Introduction}

Obesity is an avoidable medical ailment characterized by enlarged fat deposition inside the body due to augmented caloric intake and lesser physical activity ${ }^{1}$. It is an associated risk of devastating diseases and increased mortality ${ }^{2}$. Globally, World Health Organization (WHO) uses $\mathrm{BMI}$ to classify overweight and obese individuals, excluding Asians because of a much lower BMI cutoff as they have an increased risk of morbidity following obesity. In February 2000, Body Mass Index cut-offs for Asian Pacific overweight adults were reported by the $\mathrm{WHO}$ as $>23$ while $>25$ for being obese ${ }^{3}$.

The prevalence of obesity increased rapidly in developing and developed nations indicating that the tendency is mostly due to environmental, behavioral, and social changes, even though hereditary factors could be involved ${ }^{1,4,5}$. Historically, obesity was associated with socioeconomic status (SES); however, an inverse relation had been observed between the obesity prevalence and the affluence over the last five decades, predominantly in women as compared to men ${ }^{6}$.

Developing countries are going under the epidemiologic and demographic transitions progressively, including a nutritional shift characterized by the consumption of more refined sugar and fats despite grains, pulses, and carbohydrates, and the higher quantities of red meat ${ }^{7}$. A Healthy obese individual does not have any 'associated' diabetes, hypertension, and even atherosclerosis risk ${ }^{8}$. However, previous studies had shown that obesity proves to be an independent risk of cardiovascular diseases ${ }^{9}$.

Although obesity has appeared as an epidemic worldwide, it is still under-recognized in Pakistan. Pakistan is currently undergoing an obesity epidemic $^{10}$. In Pakistan, the causative factors of obesity are urbanization, environmental changes, highly dense food consumption, lifestyle modification, and physical inactivity ${ }^{5}$.

Adiposity is measured through BMl; however, it should be realized critically that all sites in the body are not equal in adiposity. Intra-abdominal (central) fat deposits compared to peripheral fat deposits are generally more strongly linked to Diabetes mellitus and insulin resistance ${ }^{11}$. Studies have demonstrated that abdominal obesity is imperative to biological ageing due to insulin resistance and glucose intolerance ${ }^{12}$. Data from the literature demonstrate that olfactory deficits are commonly found both in ageing ${ }^{13}$. Age-related atrophy is seen with ageing in nasal epithelium ${ }^{14}$. An increase in nasal volume as a function of age lowers the blood flow in the region ${ }^{15}$ as well as reduced responsiveness to autonomic stimulation ${ }^{16}$. Thereby, the study objective was to evaluate the predisposition of young obese individuals towards accelerated biological ageing and to determine that a smell test is a possible indicator for accelerated biological ageing.

\section{Methodology}

This descriptive cross-sectional study was carried out in Karachi, Pakistan, from $8^{\text {th }}$ June 2016-4 $4^{\text {th }}$ December 2019. A total of 412 communitydwelling, apparently healthy individuals with no diagnosed illness and disorder, were included in the study. The data for age, gender, SES, longevity in family, education status, marital status, BMI, sniffing score, and $\mathrm{HbA} 1 \mathrm{c}$ levels were collected from the target population. This study was approved by the institution's ethics and review board committee (Reference Number: $\mathrm{QR} / 957 / \mathrm{NMC} / 10)$. The informed consent was taken from all the participants before the start of the study.

The operational definition of healthy ageing (a focus of WHO 2015-2030) was used in the study rather than just ageing. WHO defines Healthy Ageing "as the process of developing and maintaining the functional ability that enables wellbeing in older age ${ }^{\prime \prime 17}$.

For BMI calculation, subjects were asked to take off shoes, and body mass was noted using physical balance, and height was measured, making them stand against the measuring tape. Thus, BMI was calculated by the formula: $\mathrm{BMI}=\mathrm{kg} / \mathrm{m}^{2}$. Where a person's weight was in kilograms and height was in 
meters square. WHO guideline cut-offs were used. A BMI of 30.0 or more was considered obese whereas, 25.0 to 29.9 was overweight, while the healthy range was 18.5 to 24.9 .

HbA1c test was performed by HB hemoglobin auto analyzer High-Performance Liquid Chromatography (HPLC method) (Lifotronic H8 hemoglobin analyzer). $4 \mathrm{ml}$ blood was collected by venipuncture using a vacutainer, in KEDTA tube (Lavender top). The lysis of cells was performed, and samples were incubated at $37^{\circ} \mathrm{C}$ to eliminate unstable aldimine formation. The supernatant was collected after centrifugation and injected into the HPLC system. The gradient separation was done via $\mathrm{HPLC}$ at $30^{\circ} \mathrm{C}$. The last 5 minute's chromatogram was recorded using a UV detector. The blood calibrator was used for quantification, and the peak height integration was used to calculate concentration.

Furthermore, for smell identification, screening 12 test kit of Sniffin Sticks (Burghart, MESSTECHNIK) intended to be used for examination of smell disorders in human subjects was used. The test results were used to differentiate between Normosmia, Hyposmia, and Anosmia. Sniffing scores (odors correctly identified) from The Sniffin' Sticks test manual was used, normosmia 10-12, hyposmia 6-10, anosmia 0-6 (Burghardt ${ }^{\circledR}$, Wedel, Germany). Before the beginning of the test, each patient was asked for any known odor allergies. The Sniffing sticks screening 12 test method was based on the forced-choice method; as per the instructions manual, the subject had to answer after each Sniffing stick according to the presented choice card, even if they did not detect anything. This procedure does not lead to a corruption of the score because only a statistic random value of guessing can be achieved.

The test consists of felt pens, the tips of which are impregnated with $4 \mathrm{ml}$ of odorant fluid or odorant substance dissolved in propylene glycol and an antibacterial agent. The provided kit had 12 scent pens, a holder, 12 multiple choice cards, a multilingual manual, an answer block with an answer template, an evaluation block. It was made sure that the subject had not consumed any food, drinks, or cigarettes 15 minutes before testing. The only exception was drinking water. Odor-free gloves were used during the test for presenting each test pen. Fresh pair of gloves for each individual was used. Care was taken to make sure scent pens end did not come in contact with gloves.

Before presenting the Sniffing Stick, subjects were handed out the corresponding choice card (a total of 12 cards 1-12, each corresponding to the respectively labeled pen). A respective scent pen was uncapped, and the subject was asked to inhale. A defined phrase: "Please Sniff Now" to instruct the individual to inhale was used as standard protocol mentioned by the manufacturer. The tip was held $2 \mathrm{~cm}$ below the nose medially to both nostrils, while the subject inhaled for 3-4 seconds. The individuals were asked to choose a term on the choice card (4 options printed, A-D with 3 incorrect and 1 correct option) mark the answer on the identification sheet. The procedure was repeated for each pen with a minimum pause of 30 seconds, and all answers were marked on the identification sheet.

The experiment was conducted in a well-ventilated room to avoid residual odor; the examiner washed hands with running water and wore cotton gloves. It was ensured that subjects did not eat, drink or smoke for the past 15 minutes before taking the test. Between each subtest, a gap of 3 minutes was assured, 18 no odor neutralizers used.

The answers were checked and graded using gender-based cum age-matched nomogram provided by the manufacturer. All the data was recorded in an excel sheet that was pre-designed and validated. Categorical data were presented as frequencies and percentages. All statistical calculations were done through SPSS version 18.0. Descriptive statistics were done for categorical variables, while inferential statistics were done through Pearson correlation and cross tabs. Oneway ANOVA was used to determine the age-wise alterations in the HbA1c (\%) level and smell identification ability. A $p$-value $<0.05$ was 
considered statistically significant. Box and whisker plot was used for graphical presentation.

\section{Results}

Four hundred and twelve participants were recruited in the study with a mean age of $32.65 \pm 12.6$ years. Participants were divided into three age groups 20 to 36,37 to 53, and 54 to 70 years. The study was conducted on both genders consisting of 194 females and 218 males. Out of the total, $19.9 \%$ of individuals were underweight, 58.5 \% were normal, $21.6 \%$ were overweight. It was also observed that of the total, $24 \%$ of participants were pre-diabetic due to altered $\mathrm{HbA} 1 \mathrm{c}$ levels. When the Smell Identification Test was performed, $78.6 \%$ of individuals were found to be having hyposmia, normosomia was in $20.4 \%$, and $1.0 \%$ had anosmia (Table 1).

Table 1: Characteristic features of the participants $(n=412)$

\begin{tabular}{|c|c|c|}
\hline Demographic Variables & Sub-Categories & Mean \pm SD \\
\hline Age (Years) & & $32.65 \pm 12.624$ \\
\hline $\mathrm{BMI}\left(\mathrm{kg} / \mathrm{m}^{2}\right)$ & & $22.696 \pm 5.7073$ \\
\hline W/H Ratio & & $0.8107 \pm 0.23115$ \\
\hline HbA1c (\%) & & $5.3443 \pm 0.45058$ \\
\hline \multirow[t]{2}{*}{ Sniffing Score } & & $9.00 \pm 1.654$ \\
\hline & & $\mathrm{n}(\%)$ \\
\hline \multirow[t]{2}{*}{ Gender } & Male & $218(52.9)$ \\
\hline & Female & 194(47.1) \\
\hline \multirow[t]{2}{*}{ Marital Status } & Single & $231(56.1)$ \\
\hline & Married & 181(43.9) \\
\hline \multirow[t]{3}{*}{ Age Groups (Years) } & 20 to 36 & 292(70.9) \\
\hline & 37 to 53 & $68(16.5)$ \\
\hline & 54 to 70 & $52(12.6)$ \\
\hline \multirow[t]{3}{*}{ Obesity } & Underweight & $82(19.9)$ \\
\hline & Normal & $241(58.5)$ \\
\hline & Overweight & $89(21.6)$ \\
\hline \multirow{4}{*}{$\begin{array}{l}\text { Socioeconomic Status } \\
\text { (SES) }\end{array}$} & Low SES & $143(34.7)$ \\
\hline & Middle SES & $103(25.0)$ \\
\hline & Upper Middle SES & 157(38.1) \\
\hline & Upper SES & $9(2.2)$ \\
\hline \multirow[t]{8}{*}{ Education } & Post-graduate & 91(22.1) \\
\hline & Graduate & $113(27.4)$ \\
\hline & Undergraduate & $4(1.0)$ \\
\hline & Intermediate & $32(7.8)$ \\
\hline & Matric & $40(9.7)$ \\
\hline & Secondary & $9(2.2)$ \\
\hline & Primary & $8(1.9)$ \\
\hline & Illiterate & $115(27.9)$ \\
\hline \multirow[t]{3}{*}{ Smell Identification Ability } & Anosmia & $4(1.0)$ \\
\hline & Hyposmia & $324(78.6)$ \\
\hline & Normosomia & $84(20.4)$ \\
\hline \multirow[t]{3}{*}{ Diabetes Status } & Normal & $301(73.1)$ \\
\hline & Pre-diabetic & $99(24.0)$ \\
\hline & Diabetic & $12(2.9)$ \\
\hline
\end{tabular}

*HbA1c-hemoglobin A1c; BMI-Body Mass Index; W/H Ratio-Waist to Hip Ratio 
Out of the total, 301 subjects were normal, 99 were pre-diabetic, and 12 were diabetic. SES, education, marital status, BMI and age significantly affected the HbA1c level among the studied population $(p<0.05)$. Table 2 shows the association of HbA1c with our study characteristics.

Table 2: Association of HbA1c Level with study characteristics

\begin{tabular}{|c|c|c|c|c|c|}
\hline \multirow[t]{2}{*}{ Variable } & & \multicolumn{3}{|c|}{ HbA1c n(\%) } & \multirow[t]{2}{*}{$p$-value } \\
\hline & & $\begin{array}{l}\text { Normal } \\
(n=301)\end{array}$ & $\begin{array}{l}\text { Pre-diabetes } \\
\quad(n=99)\end{array}$ & $\begin{array}{c}\text { Diabetes } \\
(n=12)\end{array}$ & \\
\hline \multirow[t]{2}{*}{ Gender } & Male & $169(56.1)$ & $45(45.5)$ & $4(33.3)$ & \multirow[t]{2}{*}{0.070} \\
\hline & Female & 132(43.9) & $54(54.5)$ & $8(66.7)$ & \\
\hline \multirow[t]{4}{*}{ SES } & Middle SES & $73(24.3)$ & $30(30.3)$ & - & \multirow[t]{4}{*}{$0.000^{*}$} \\
\hline & Upper middle SES & $108(35.9)$ & $37(37.4)$ & $12(100)$ & \\
\hline & Low SES & $111(36.9)$ & $32(32.3)$ & - & \\
\hline & Upper SES & $9(3.0)$ & - & - & \\
\hline \multirow[t]{8}{*}{ Education } & Post-graduate & $66(21.9)$ & $21(21.2)$ & $4(33.3)$ & \multirow[t]{8}{*}{$0.000^{*}$} \\
\hline & Graduate & $81(26.9)$ & $32(32.3)$ & - & \\
\hline & Undergraduate & $4(1.3)$ & - & - & \\
\hline & Intermediate & $24(8.0)$ & $4(4.0)$ & $4(33.3)$ & \\
\hline & Matric & $24(8.0)$ & $12(12.1)$ & $4(33.3)$ & \\
\hline & Secondary & $4(1.3)$ & $5(5.1)$ & - & \\
\hline & Primary & $8(2.7)$ & - & - & \\
\hline & Illiterate & $90(29.9)$ & $25(25.3)$ & - & \\
\hline \multirow[t]{2}{*}{ Marital status } & Single & $195(64.8)$ & $36(36.4)$ & - & \multirow[t]{2}{*}{$0.000 *$} \\
\hline & Married & $106(35.2)$ & $63(63.6)$ & $12(100)$ & \\
\hline \multirow[t]{3}{*}{ Obesity } & Underweight & $74(24.6)$ & $8(8.1)$ & - & \multirow[t]{3}{*}{$0.003^{*}$} \\
\hline & Normal & $168(55.8)$ & $65(65.7)$ & $8(66.7)$ & \\
\hline & Overweight & $59(19.6)$ & $26(26.3)$ & $4(33.3)$ & \\
\hline \multirow[t]{3}{*}{ Age Group } & 20 to 36 & $244(81.1)$ & $48(48.5)$ & - & \multirow[t]{3}{*}{$0.000 *$} \\
\hline & 37 to 53 & $49(16.3)$ & 19(19.2) & - & \\
\hline & 54 to 70 & $8(2.7)$ & $32(32.3)$ & $12(100)$ & \\
\hline \multirow[t]{2}{*}{ Longevity } & Present & $235(78.1)$ & 71(71.7) & $8(66.7)$ & \multirow[t]{2}{*}{0.320} \\
\hline & Absent & $66(21.9)$ & $28(28.3)$ & $4(33.3)$ & \\
\hline
\end{tabular}

*Statistically significant; SES-Socioeconomic Status; *HbA1c-hemoglobin A1c 


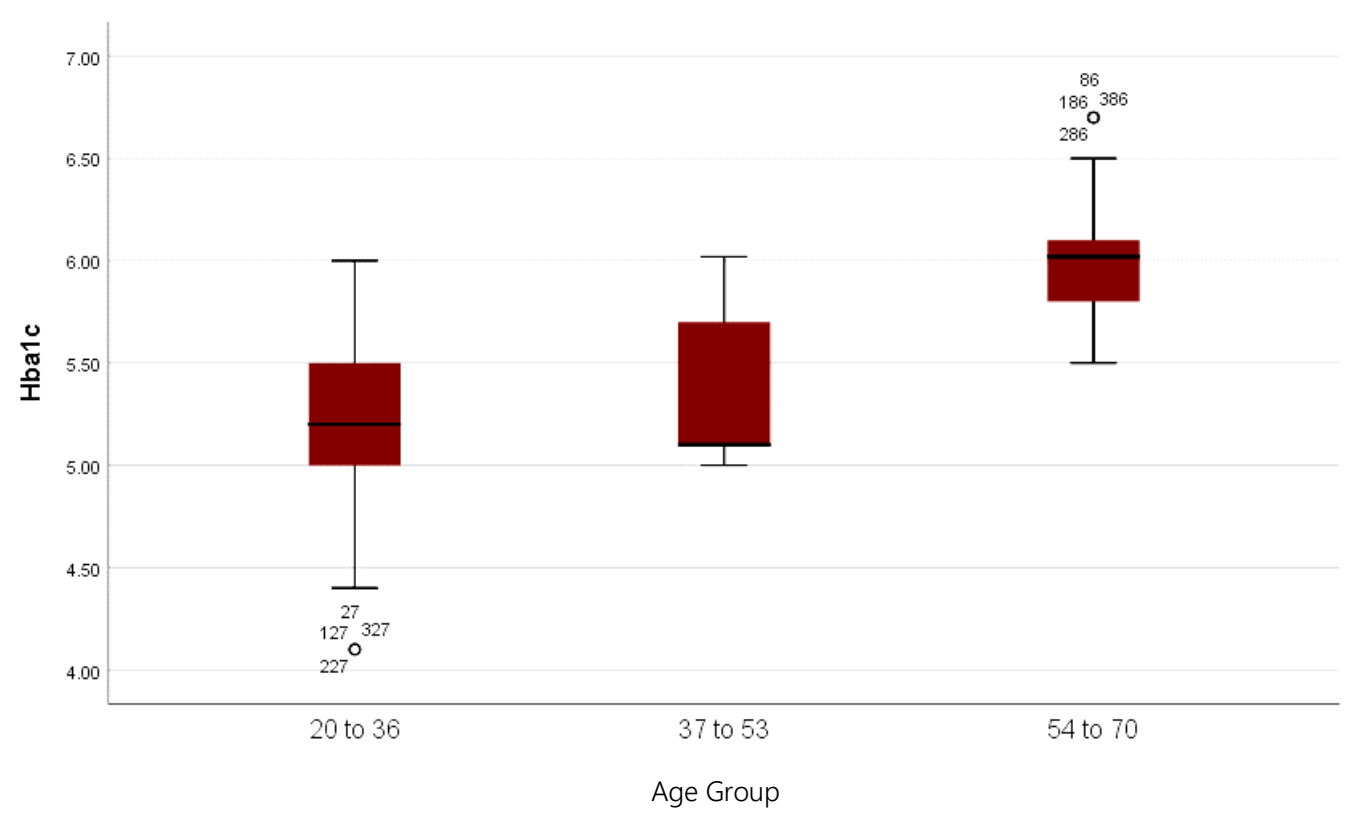

Figure 1: Whisker Plot showing the HbA1c levels stratified by age

The HBA1c level also significantly increased (median; $25^{\text {th }}-75^{\text {th }}$ percentiles) from $5.20 ; 5.00-5.50 \%$ among 20 to 36 years age group to 6.02; 5.80-6.10\% among 54 to 70 years subjects (Figure 1). The sniff score (smell identification ability) decreased from 9.0; 8.0-11.0 among 20 to 36 years age group to 7.0; 7.0-9.0 among 54 to 70 years age group (Figure 2).

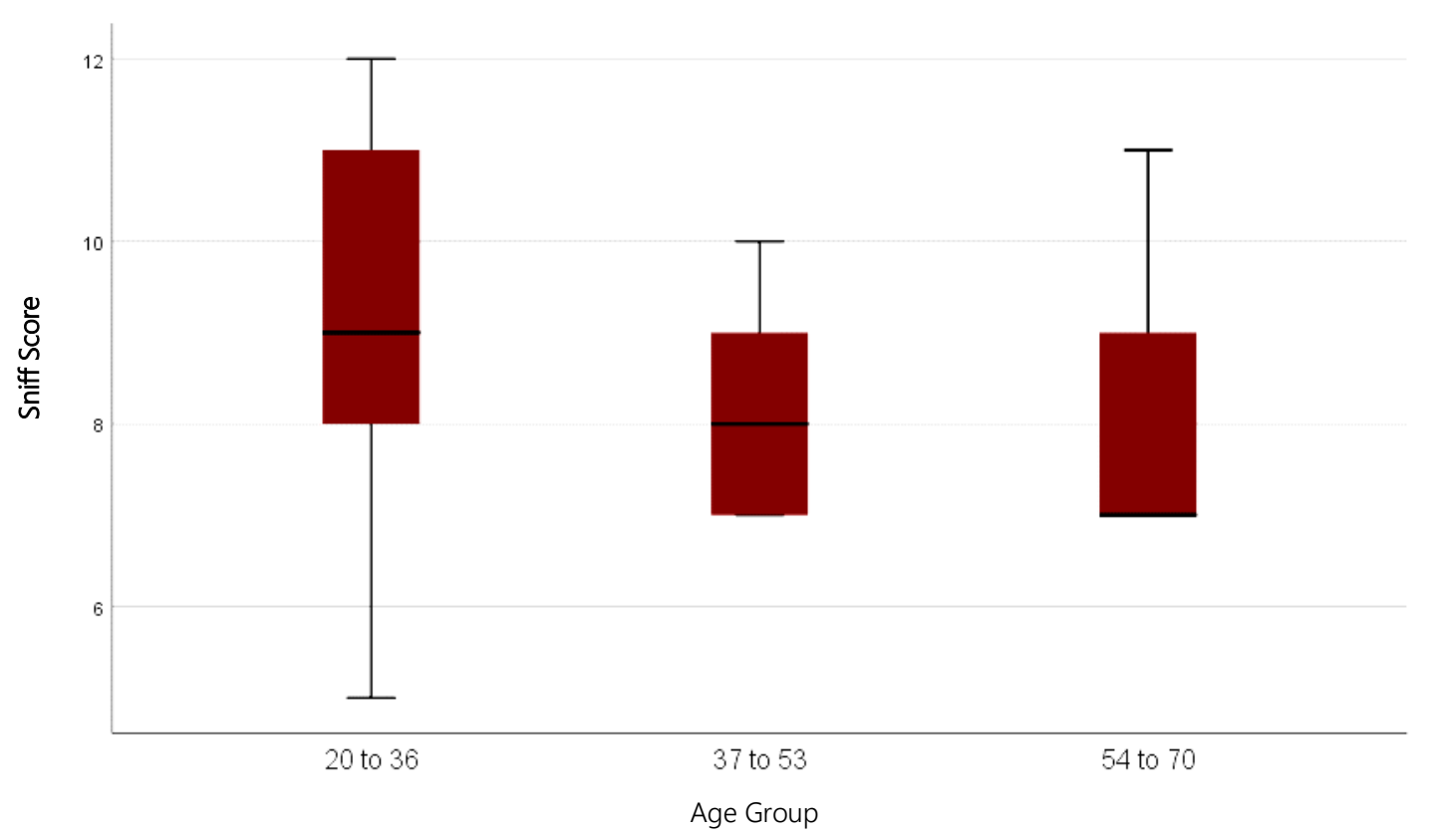

Figure 2: Whisker Plot showing the sniff score stratified by age (Smell Identification Test). 
The majority of the enrolled study participants were hyposmic $(n=324)$, the smell identification ability was significantly associated with socioeconomic status, education, marital status, obesity, age and longevity $(p<0.05)$ (Table 3).

Table 3: Association of Smell Identification Ability (Sniff Score) with study characteristics

\begin{tabular}{|c|c|c|c|c|c|}
\hline \multirow[t]{2}{*}{ Variable } & & \multicolumn{3}{|c|}{ Smell Identification-Sniff Score n(\%) } & \multirow[t]{2}{*}{$p$-value } \\
\hline & & $\begin{array}{c}\text { Anosmia } \\
(n=4)\end{array}$ & $\begin{array}{c}\text { Hyposmia } \\
(\mathrm{n}=324)\end{array}$ & $\begin{array}{c}\text { Normosmia } \\
\quad(n=84)\end{array}$ & \\
\hline \multirow[t]{2}{*}{ Gender } & Male & $4(100)$ & $174(53.7)$ & $40(47.6)$ & \multirow[t]{2}{*}{0.101} \\
\hline & Female & - & $150(46.3)$ & $44(52.4)$ & \\
\hline \multirow[t]{4}{*}{ SES } & Middle SES & - & $83(25.6)$ & $20(23.8)$ & \multirow[t]{4}{*}{$0.031^{*}$} \\
\hline & $\begin{array}{l}\text { Upper middle } \\
\text { SES }\end{array}$ & $4(100)$ & $129(39.8)$ & $24(28.6)$ & \\
\hline & LOW SES & - & 107(33.0) & $36(42.9)$ & \\
\hline & Upper SES & - & $5(1.5)$ & $4(4.8)$ & \\
\hline \multirow[t]{8}{*}{ Education } & Post-graduate & - & $79(24.4)$ & $12(14.3)$ & \multirow[t]{8}{*}{$0.000 *$} \\
\hline & Graduate & - & $81(25.0)$ & $32(38.1)$ & \\
\hline & Undergraduate & - & - & $4(4.8)$ & \\
\hline & Intermediate & $4(100)$ & $24(7.4)$ & $4(4.8)$ & \\
\hline & Matric & - & $24(7.4)$ & $16(19.0)$ & \\
\hline & Secondary & - & $9(2.8)$ & - & \\
\hline & Primary & - & $8(2.5)$ & - & \\
\hline & Illiterate & - & $99(30.6)$ & $16(19.0)$ & \\
\hline \multirow[t]{2}{*}{ Marital status } & Single & - & $179(55.2)$ & $52(61.9)$ & \multirow[t]{2}{*}{$0.042^{*}$} \\
\hline & Married & $4(100)$ & $145(44.8)$ & $32(38.1)$ & \\
\hline \multirow[t]{3}{*}{ Obesity } & Underweight & - & $62(19.1)$ & $20(23.8)$ & \multirow[t]{3}{*}{$0.000^{*}$} \\
\hline & Normal & $4(100)$ & $205(63.3)$ & $32(38.1)$ & \\
\hline & Overweight & - & $57(17.6)$ & $32(38.1)$ & \\
\hline \multirow[t]{3}{*}{ Age Group } & 20 to 36 & $4(100)$ & $212(65.4)$ & $76(90.5)$ & \multirow[t]{3}{*}{$0.000^{*}$} \\
\hline & 37 to 53 & - & $68(21.0)$ & - & \\
\hline & 54 to 70 & - & $44(13.6)$ & $8(9.5)$ & \\
\hline \multirow[t]{2}{*}{ Longevity } & Present & $4(100)$ & $254(78.4)$ & $56(66.7)$ & \multirow[t]{2}{*}{$0.042^{*}$} \\
\hline & Absent & - & $70(21.6)$ & 28(33.3) & \\
\hline
\end{tabular}

*Statistically significant

\section{Discussion}

Obesity is an associated risk of debilitating diseases and increased mortality ${ }^{1}$. In Pakistan, the causative factors of obesity are urbanization, environmental changes, highly dense food consumption, lifestyle modification, and physical inactivity ${ }^{5}$. Adiposity is measured through $\mathrm{BMl}$; however, it should be realized critically that all sites in the body are not equal in adiposity. The intra-abdominal (central) fat deposits as compared to peripheral fat deposits are more strongly linked to Diabetes mellitus and insulin resistance ${ }^{11}$. Therefore, it was hypothesized that obese individuals are inclined towards an accelerated ageing process. A total of 412 individuals were recruited in the study and divided into three age groups: 20 to 36,37 to 53 , and 54 to 70 years. The genders were included in the study 194 (47.1\%) females and 218 (52.9\%) males. Out of the total, 89 (21.6\%) were obese, and 99 (24\%) were pre-diabetic.

When the association between body physique (BMI) and predisposition to diabetes ( $\mathrm{HbA1c}$ ) was 
observed, it was found that the HbA1c level becomes altered with obesity and the risk of predisposition to diabetes increases with increased BMI significantly $(p=0.003)$. This is because enlarged fat cell releases leptin in large quantities. Followed by Leptin deficiency that ultimately leads to obesity ${ }^{19,20}$. The fat cell's increased size is mainly attributed to the amplified free fatty acids' concentration, thereby producing modifications in the cholesterol metabolism and insulin clearance by the liver, ultimately leading to the increased gall bladder disease and diabetes risk following obesity $^{21}$. Therefore, researchers have considered obesity as the strongest predictor of type II diabetes mellitus ${ }^{22}$. And thus its development typically depends on changes in one or both insulin sensitivity and insulin secretion, which could be modified by obesity ${ }^{23}$.

Besides, when the association between body physique (BMI) and olfaction (smell identification test) was observed, it was found that the risk of decreased smell identification ability was almost equally prevalent in underweight, normal, and overweight individuals. Hence, a statistically significant association $(p=0.000)$ showing an increased risk of hyposmia and anosmia with increased BMI was concluded. These results were in agreement with the previous studies. Researches have demonstrated that abdominal obesity is imperative to biological ageing due to insulin resistance and glucose intolerance ${ }^{12}$. Whereas, disorders of olfaction are generally associated with advancing age, especially affecting the elderly people who have cognitive impairment ${ }^{24}$. Thereby, it was confirmed through the results that decreased sense of olfaction at younger ages is untimely predisposing obese individuals towards accelerated ageing.

However, when the cross-analysis was done between the age groups, their BMl status, and smell identification test, it was observed that olfaction was decreasing in all age groups irrespective of BMI. Statistically non-significant association $(p=0.765)$ was found between the two variables. Recent research confirmed these results, which showed that obesity or increased BMI causes malfunctioning of the hypothalamus. This is ultimately leading to an imbalance between the intake of calories and energy expenditure, which results in a decreased life span due to a positive balance of energy ${ }^{25}$.

Additionally, when the cross-analysis was done between the age groups, their predisposition to diabetes and smell identification test, it was observed that olfaction was decreasing in all age groups as the HbA1c levels were increasing. Statistically non-significant association $(p=0.106)$ but showing altered olfaction in age groups, specifically in the age group of 37-53 years as the risk of diabetes increases due to altered $\mathrm{HbA} 1 \mathrm{c}$ levels, thereby proving accelerated ageing in the diabetic and pre-diabetic young individuals considering altered olfaction as a possible indicator of ageing. The current results were similar to previous research, which revealed that olfaction test gave non-significant results between the patients with and without complications of diabetes $^{26}$. A decline in cognitive functions are a hallmark of diabetes that leads to late-onset dementia ${ }^{27}$. The Mona Lisa Study highlighted that obesity and increased blood glucose is directly linked with poor cognitive impairment and is already evident in middle-aged individuals ${ }^{28}$. Studies have suggested that olfaction disorders are basically due to neuro-degeneration and could occur as a diabetic complication ${ }^{29}$. Since impaired olfaction is an indicator of ageing in the elderly, but it was observed in the early ages in the current study due the presence of diabetes and obesity in the study participants. These results confirms the findings of the previous research where obesity and diabetes were predisposing individuals towards accelerated ageing ${ }^{30}$.

As olfaction was subsiding with an increase in BMI and $\mathrm{HbA1c}$ levels, it was concluded that obese individuals are going towards accelerated biological ageing and their predisposition towards diabetes due to obesity is increasing. The study's novelty lies in the finding that the smell identification test was accepted as a physiological indicator of ageing. In the wake of such findings, exercise is highly recommended if Pakistan wants 
to reduce the non-communicable diseases' burden within the next two decades. Otherwise, the longterm effects would be anything but beneficial in children and adults ${ }^{31}$.

The limitations of the study were family history of Parkinson's was not included in the screening of subjects. Subjects from all socioeconomic classes could not be added due to lack of their prior exposure to a couple of odors that were included in the set of The Sniffin Sticks Test. An equal number of participants were not included in each group. Further, gender-based differences could not be ascertained.

\section{Conclusion}

The novelty of the study lies in screening the local population for Smell Identification Ability, the sniffing score. It is concluded that a considerable percentage of our population is suffering from the lower olfactory performance that goes unscreened. Hyposmia, if screened early, can predict the predisposition of subjects towards disorders in which neurodegeneration plays a crucial role. Hence, the biological ageing of these subjects is accelerated as compared to chronologically agematched subjects with normosmia.

\section{Conflicts of Interest}

None.

\section{Acknowledgement}

The Authors would like to acknowledge Hafsa Farooq \& Khadija Shabbir for their assistance during the study.

\section{Funding}

None.

\section{References}

1. James PT, Leach R, Kalamara E, Shayeghi M. The worldwide obesity epidemic. Obes Res. 2001;9(S11):228S-233S

2. WHO. Preventing and managing the global epidemic of obesity. Report of the World Health Organization Consultation on Obesity. Geneva:
World Health Organization; 1997.

3. WHO. Obesity: preventing and managing the global epidemic. World Health Organization; 2000.

4. Hodge AM, Zimmet PZ. The epidemiology of obesity. Best Pract. Res. Clin. Endocrinol. 1994;8(3):577-599.

5. Nanan D. The obesity pandemic--implications for Pakistan. J Pak Med Assoc. 2002;52(8):342.

6. United States Government Printing Office, Usgpo. National Institute of Health. Alternative medicine: Expanding medical horizons: A report to the National Institutes of Health on alternative medical systems and practices in the United States. Health and Human Services Department; 1995.

7. Popkin BM, Paeratakul S, Zhai F, Ge K. A review of dietary and environmental correlates of obesity with emphasis on developing countries. Obes Res. 1995;3(S2):145s-153s.

8. Wildman RP, Muntner P, Reynolds K, McGinn AP, Rajpathak S, Wylie-Rosett J, Sowers MR. The obese without cardiometabolic risk factor clustering and the normal weight with cardiometabolic risk factor clustering: prevalence and correlates of 2 phenotypes among the US population (NHANES 1999-2004). Arch Int Med. 2008;168(15):1617-1624.

9. Hubert HB, Feinleib M, McNamara PM, Castelli WP. Obesity as an independent risk factor for cardiovascular disease: a 26-year follow-up of participants in the Framingham Heart Study. Circulation. 1983;67(5):968-977.

10. Tanzil S, Jamali T. Obesity, an emerging epidemic in Pakistan-a review of evidence. J Ayub Med Coll Abbottabad. 2016;28(3):597.

11. Kissebah AH, Krakower GR. Regional adiposity and morbidity. Physiol Rev. 1994;74(4):761-811.

12. Jura M, Kozak LP. Obesity and related consequences to ageing. Age. 2016;38(1):23.

13. Gilbert PE, Pirogovsky E, Ferdon S, Murphy C. The effects of normal aging on source memory for odors. J Gerentol B-Psychol. 2006;61(1):P58-P60.

14. Murphy C, Nunez K, Withee J, Jalowayski AA. The Effects of Age, Nasal Airway-Resistance And Nasal Cytology On Olfactory Threshold For Butanol. In Chemical Senses. Walton St Journals Dept, Oxford, England Ox2 6dp: Oxford Univ Press. 1985;10(3):418.

15. Bende M. Blood flow with $133 \mathrm{Xe}$ in human nasal mucosa in relation to age, sex and body position. 
Acta oto-laryngol. 1983;96(1-2):175-179.

16. Hasegawa M, Kern E. The human nasal cycle. Paper presented at: Mayo Clin Proceed. 1977.

17. World Health Organization. Health in 2015: from MDGs, millennium development goals to SDGs, sustainable development goals; 2015.

18. Rumeau C, Nguyen D, Jankowski R. How to assess olfactory performance with the Sniffin'Sticks test ${ }^{\circledR}$. Eur Ann Otorhinolaryngol Head Neck Dis. 2016;133(3):203-206.

19. Loos RJ. Genetic determinants of common obesity and their value in prediction. Best Pract. Res. Clin. Endocrinol. 2012;26(2):211-226.

20. Farooqi IS, O'Rahilly S. Genetic factors in human obesity. Obes Rev. 2007;8:37-40.

21. Bonfrate L, Wang DQ, Garruti G, Portincasa P. Obesity and the risk and prognosis of gallstone disease and pancreatitis. Best Pract. Res. Clin. Gastroenterol. 2014;28(4):623-635.

22. Menke A, Rust KF, Fradkin J, Cheng YJ, Cowie CC. Associations between trends in race/ethnicity, aging, and body mass index with diabetes prevalence in the United States: a series of crosssectional studies. Ann Intern Med. 2014;161(5):328335.

23. DeFronzo RA, Ferrannini $E$, Groop L, Henry RR, Herman WH, Holst JJ, Hu FB, Kahn CR, Raz I, Shulman Gl, Simonson DC. Type 2 diabetes mellitus. Nat Rev Dis Prim. 2015;1(1):1-22.

24. Gros A, Manera V, De March CA, Guevara N, König A, Friedman L, Robert P, Golebiowski J, David R. Olfactory disturbances in ageing with and without dementia: towards new diagnostic tools. J Laryngol Otol. 2017;131(7):572-579.

25. Cavadas C, Aveleira CA, Souza GF, Velloso LA. The pathophysiology of defective proteostasis in the hypothalamus-from obesity to ageing. Nat Rev Endocrinol. 2016;12(12):723-733.

26. Kaya KS, Mazı EE, Demir ST, Tetik F, Tuna M, Turgut S. Relationship between progression of type 2 diabetes mellitus and olfactory function. Am J Otolaryngol. 2019:102365.

27. Biessels GJ, Staekenborg S, Brunner E, Brayne C, Scheltens P. Risk of dementia in diabetes mellitus: a systematic review. Lancet Neurol. 2006;5(1):64-74.

28. Sanz CM, Ruidavets JB, Bongard V, Marquié JC, Hanaire $H$, Ferrières $J$, Andrieu $S$. Relationship between markers of insulin resistance, markers of adiposity, $\mathrm{HbA} 1 \mathrm{c}$, and cognitive functions in a middle-aged population-based sample: the MONA LISA study. Diabetes care. 2013;36(6):1512-21.

29. Kim SJ, Windon MJ, Lin SY. The association between diabetes and olfactory impairment in adults: A systematic review and meta - analysis. Laryngo Invest Otolaryngol. 2019;4(5):465-475.

30. Marciniak A, Mielnik-Niedzielska G. Smell dysfunction from symptoms to diagnosis-recent methods of olfactory function assessment. J Edu Health Sport. 2019;9(2):235-242.

31. Mirza F. Obesity; An outcome of abnormal eating behavior. Ann Psychophysiol. 2018;5(5):1-5. 